\title{
Molecular Targeting of Nrf2 and NFkB Signaling by 3-Acetyl-11-Keto- $\beta$-Boswellic Acid and Piperine Against Fluid Percussion Rat Model of Traumatic Brain Injury
}

\section{Satyabrata Kundu}

ISF College of Pharmacy

Shamsher Singh ( $\sim$ shamshersinghbajwa@gmail.com )

ISF College of Pharmacy https://orcid.org/0000-0002-2780-6632

\section{Research Article}

Keywords: Traumatic brain injury, LFPI, AKBA, Piperine, Neuroinflammation

Posted Date: November 8th, 2021

DOI: https://doi.org/10.21203/rs.3.rs-993276/v1

License: (c) (i) This work is licensed under a Creative Commons Attribution 4.0 International License.

Read Full License 


\section{Abstract}

Traumatic brain injury in rats through lateral fluid percussion injury (LFPI) model causes elevation of intracranial pressure which leads to impairment in motor and cognitive behaviour. 3-acetyl-11-keto- $\beta$ boswellic acid (AKBA) is a well-known anti-inflammatory agent but it has very low bioavailability. The current study was established to investigate the neuroprotective effect of AKBA in combination with bioenhancer piperine in LFPI induced TBI in experimental rats. Fluid percussion injury was introduced in the brain by delivering $50 \mathrm{mmHg}$ of pressure for 3 minutes to the exposed brain. AKBA $25 \mathrm{mg} / \mathrm{kg}$ and 50 $\mathrm{mg} / \mathrm{kg}$ orally and AKBA ((25 mg/kg, p.o.) in combination with piperine $(2.5 \mathrm{mg} / \mathrm{kg}$, p.o.) was administered from day 1 to day 14 . On the $1^{\text {st }}, 7^{\text {th }}$ and $14^{\text {th }}$ day, behavioural parameters were checked. On the $15^{\text {th }}$ day, animals were euthanized. Then the cortex was isolated for the estimation of biochemical levels (MDA, nitrite, reduced $\mathrm{GSH}$, catalase), neuroinflammatory markers (TNF- $\alpha, \mathrm{IL}-1 \beta, \mathrm{IL}-6)$, and neurotransmitters (norepinephrine, dopamine, 5-HT, GABA, glutamate). From animals, hippocampus and cortex were isolated for histopathological analysis, and expressions of Nrf2 and NFkB were measured by the immunohistological study. Treatment with AKBA significantly attenuated LFPI induced abnormalities, biochemical and neurotransmitter changes in experimental rats. Further finding AKBA in combination with piperine significantly prevented histopathological changes, increased Nrf2 positive cells and reduced NFkB expression in the cortical region. The present study concluded that AKBA along with piperine achieved anti-oxidant, anti-inflammatory, neuro-modulatory effects as well as prevented neuronal injury via targeting Nrf2 and NFkB.

\section{Introduction:}

Worldwide, traumatic brain injury (TBI) causes disability followed by death in between teenagers and adults (Langlois et al. 2006). The rate of injuries is increasing yearly. TBI can be demonstrated as an alteration of normal brain physiology that results from sudden external mechanical injury to the skull (Maneshi et al. 2015). Road accidents are the major cause of head injury; however, falls are the leading cause of post-TBI morbidity (Galgano et al. 2017). TBI significantly impairs the healthcare system of the body and also alters the socio-economical status of patients, and is often tagged as a silent epidemic. The long-term sequelae of diffuse TBI impair cognition, emotional and sensory functions (McKee and Daneshvar. 2015). Post-TBI neurovascular outcomes require experimentation that involves circulatory, immune alteration, nervous systems in vivo rather than in vitro and in silico modeling.

Various well-established animal models of TBI are available for neurotrauma investigations and each model deals with specific clinical etiology. The fluid percussion injury (FPI) model is a commonly used and well-characterized preclinical TBI model (Lifshitz et al. 2016). FPI model was established for the establishment of midline injury, later it was modified to lateral injury in adult rats. Post-TBI observable effects including transient apnoea, seizure activities are very common (Kharatishvili et al. 2006). The outcome that was investigated following FPI is neuronal damage which results in neuralgia after 7 days of injury. 3-acetyl-11-keto- $\beta$-boswellic acid (AKBA) is a pentacyclic triterpenoid compound obtained from the resinous extract of Boswellia serrata. This plant is used widely in different diseases including 
respiratory, rheumatic arthritis, tumours, and liver disease (Takada et al. 2006). The main bioactive compound of Boswellia is boswellic acid, mainly AKBA, which shows anti-inflammatory and anti-oxidant properties (Beghelli et al. 2017; Cuaz-Pérolin et al. 2008).

Nuclear factor-erythroid 2-related factor 2 (Nrf2), a nuclear factor which grabs researchers' attention in recent years (Kobayashi and Yamamoto. 2006). Various reports showed that Nrf2 is involved in different pathological consequences including reperfusion injury, nervous systems (Kandhare et al. 2015; Wang et al. 2012). Mainly, Nrf2 is present in the cytoplasm in normal conditions in association with Kelch-like $\mathrm{ECH}$-associated protein 1 (Keap1), but under pathological conditions, the cysteine residue of Keap1 promotes the release of Nrf2. However, the Nrf2 is then translocate to the nucleus and attached to the antioxidant response element (ARE) and subsequently triggers various downstream protective factors (HO-1, NADPH: quinine oxidoreductase 1), which further regulates intracellular redox balance (de Vries et al. 2008; Itoh et al. 2004). The goals of the current study are to investigate the role of AKBA treatment following LFPI, check neurological insufficiencies in rats, and determination of the neuroprotective effect of Nrf2/HO-1 activator AKBA.

\section{Materials And Methods 2.1. Animals}

For the current research protocol, male wistar rats (200-230 g) were procured from ISF College of Pharmacy, Moga, Punjab, India. The animals were kept in a 12-hour light/dark cycle and maintained the room temperature of $22 \pm 1^{\circ} \mathrm{C}$. Before experimenting, the protocol was checked and approved by Institutional Animal Ethics Committee (IAEC). The procedures of handling and maintaining were followed according to the guidelines given by the Committee for the Purpose of Control and Supervision of Experiments on Animals (CPCSEA), India.

\subsection{AKBA and other chemicals}

AKBA and piperine were procured from Sigma Aldrich, India. ELISA kits (TNF-a, IL-1 $\beta$, IL-6) were purchased from Abcam, USA. Nrf2 antibody and NF-kB antibody kits were purchased from ELK Biotechnology, Wuhan. All the chemicals were freshly prepared before starting the experimental procedures.

\subsection{Craniotomy}

Before starting the experiment, the rats were anaesthetized with an intraperitoneal injection of ketamine $(65 \mathrm{mg} / \mathrm{kg})$ and xylazine $(10 \mathrm{mg} / \mathrm{kg})$. Anaesthetized rats were placed in the stereotaxic surgery frame in a prone position. A midline incision $(2-\mathrm{cm})$ was made from the eyes towards the neck by using a surgical blade, and the skin was flapped for exposing the right parietal bone. The location of the craniotomy was selected in the right hemisphere midpoint of bregma and lambda. The craniotomy was performed using the drill machine. The bone dust was cleaning continuously to prevent any further damage to the dura. After the craniotomy, a micropipette tip was attached to the surgery area of the skull and sealed with 
dental cement. The micropipette tip $(1 \mathrm{ml})$ was filled with $5 \%$ dextrose solution and then attached with a sphygmomanometer connecting tube for delivering fluid pressure.

\subsection{Fluid percussion injury (FPI)}

The lateral fluid percussion injury model was used to create mild traumatic brain injury. This model causes injury by inducing fluid pressure through a sphygmomanometer into the skull. The sphygmomanometer rubber tube is connected with a Y-tube connector. One arm of this tube connector was linked with the cuff and other one was connected with a micro-pipette tip. After the surgical procedure was done, the micro-pipette tip was fixed onto the skull at the craniotomy region. After gaining normal respiration, the fluid pressure of $50 \mathrm{mmHg}$ was delivered through a sphygmomanometer for 3 minutes to the brain. Following the LFPI, the tip was removed very deliberately. The skin was then sutured and the rats were placed in sterilized cages and then housed.

\subsection{Experimental design}

After the habituation period was over, the rats were trained in grip strength test, rotarod apparatus, beam crossing task, open field test and Morris water maze for 5 days. After the completion of training, rats were distributed randomly into the following groups- Group I: Normal, Group II: TBI control, Group III: TBI+ piperine (2.5 mg/kg), Group IV: TBI+AKBA (25 mg/kg), Group V: TBI+AKBA (50 mg/kg), and Group Vl: TBI+ piperine $(2.5 \mathrm{mg} / \mathrm{kg})+$ AKBA (25 mg/kg) (Table 1). The drug administration was started from day 1 of injury to day 14 . On the $1 \mathrm{st}$, 7 th, and 14 th day of post-injury, the behavioral study was performed. On the 15th day, the cervical dislocation method was proceeded to sacrifice animals and then brains were taken out and kept at $-80^{\circ} \mathrm{C}$. On the day of analysis (15th day), the cortex part was isolated for analysing biochemicals (MDA, nitrite, glutathione, catalase), neuroinflammatory markers (TNF-a, IL-1 $\beta, I L-6)$, and neurotransmitters (norepinephrine, dopamine, 5-HT, GABA, glutamate). Some isolated brains were kept in 10\% formalin at room temperature for histological and immunohistological studies (Fig. 1).

\subsection{Neurobehavioral studies}

\subsubsection{Grip strength}

The gripping ability of rat forelimbs was analyzed by grip strength apparatus (Make: Chatillon). Before initiating the protocol, the rats were trained carefully. During the experimental session, rats were individually placed on apparatus and free to grab the mesh with forelimbs. Then rats were pulled back by the tail to record the grip strength reading in $\mathrm{KgF}$ (Anderson et al. 2005).

\subsubsection{Rotarod test}

The rotarod apparatus (Model: Medicraft 519/E-40, INCO) was used to evaluate the motor coordination of rats (Carter et al. 2001). The rats were pre-trained for 5 days (three sessions per day) to acclimatize the rotarod activity. On the rotating rod ( $25 \mathrm{rpm}$ speed), rats were placed and free to walk on rod. The cut-off time was 3 minutes. On the rotating rod, the average retention time on rotating rod was recorded for evaluation. 


\subsubsection{Open field test}

The open field test apparatus was used to evaluate the locomotion and exploration using wooden, square, greyish white colored apparatus $(100 \mathrm{~cm} \times 100 \mathrm{~cm}$, wall: $35 \mathrm{~cm}$ high). The apparatus was designed with 25 sub-square $(20 \mathrm{~cm} \times 20 \mathrm{~cm})$ on the floor of the apparatus. The rat was introduced at the middle of the apparatus and the primary free exploration time was for 5 minutes. The exploratory behavior alteration for each group was observed. After conducting each test, the floor of the apparatus was cleaned with a wet cloth. During the observation, line crossing counts (crossing of one square with forelimbs), rearing (stands with the hind legs), and grooming (mouth or head rubbing with paws) were recorded and the scoring was done by a blind observer (Kumar et al. 2011).

\subsubsection{Narrow beam task}

This test was performed to evaluate the motor coordination and function by checking the ability of animals to cross the narrow beam. The beam was made up of two platforms (start point and end point) and connected by a wooden beam (length: $100 \mathrm{~cm}$, width: $5.5 \mathrm{~cm}$, and thickness: $1 \mathrm{~cm}$ ). The beam was $100 \mathrm{~cm}$ above the ground. A sponge pad was placed on the ground below the beam to prevent another injury during the performance. For the acclimatization to the wooden beam, the rats were allowed for 5 minutes of exploration before processing of training phase. The training session was started by placing the rats on the starting point. During travelling onto the beam, the slipping of foot occurred. Time taken to travel the beam and the numbers of foot slips during travelling were recorded (Karunanithi et al. 2011).

\subsubsection{Morris water maze}

To check the spatial and learning memory impairment after TBI, the Morris water maze was used (Moris. 1984). This apparatus was made up of an iron-coated round pool (diameter 6 feet $x$ height 3 feet). Tap water was used for filling up the maze and the controlled temperature of the water was at $26 \pm 1{ }^{\circ} \mathrm{C}$. The cotton thread was used for dividing the maze into four equal quadrants. During the acquisition phase, one quadrant was selected for keeping a round platform ( $5 \mathrm{~cm}$ diameter) just $1 \mathrm{~cm}$ above the water level, but during the retention phase, the pool water volume was increased to maintained the platform $1.5 \mathrm{~cm}$ below the water level. The animals were placed in the pool one by one for four times and the gap between the two training sessions was 5 minutes. The animals were placed at the first quadrant and recorded the time taken by each animal to reach the platform. Then the rats were permitted to sit on the round platform for 20 seconds. If the rat was able to find the platform within 2 minutes, represents good training. But if the rat was unable to find the platform within the given time, the same was guided to find the platform and stay in the same position for the next 20 seconds. After 24 hours of the last training session, a probe trial was also conducted. The time spent in the target quadrant (TSTQ) was recorded and it showed learning as well as spatial memory function after training. After the training period was over, the escape latency was checked, and then milk was poured into water to make the pool opaque. For checking the final spatial memory, TSTQ and escape latency was measured.

\subsection{Biochemical parameters studies}


2.7.1. Dissection and homogenization: On the 15th day, animals were sacrificed and immediately removed the brain samples and placed on ice for isolating the cortex, and also for different brain morphological evaluations. The isolated brains were rinsed with ice-cold saline $(0.9 \%)$ for biochemical estimation, and further processing was conducted in cold conditions $\left(-4^{\circ} \mathrm{C}\right)$. After weighing each isolated brain sample, they were homogenized in phosphate buffer $(0.1 \mathrm{M})$ with a $\mathrm{pH} 7.4$, and subsequently centrifuged for 15 minutes at 10,000g and the supernatant were separated for the estimation of biochemical markers.

2.7.2. Measurement of MDA: The concentration of the malondialdehyde (MDA) in the cortical region was measured and the procedure was completed according to the method of wills et al (Wills. 1966). The MDA concentration (measurement of lipid peroxidation) was analyzed via reaction with thiobarbituric acid at a wavelength of $532 \mathrm{~nm}$ using a spectrophotometer (UV-1700, Shimadzu, Japan). The estimated values were expressed in $\mathrm{nmol} / \mathrm{mg}$ tissue protein.

2.7.3. Estimation of nitrite: The nitrite accumulation in cortical supernatant was determined by colorimetric assay using Griess reagent (0.1\% N-(1-naphthyl) ethylene diamine dihydrochloride, $1 \%$ sulfanilamide and $2.5 \%$ phosphoric acid) according to the method described by Green et al (Green. 1982). Both the supernatant and Griess reagent were mixed in equal volume and incubated for 10 minutes at $37^{\circ} \mathrm{C}$. Absorbance of the final solution was measured at $540 \mathrm{~nm}$ in a spectrophotometer (UV1700, Shimadzu, Japan) and expressed as $\mu \mathrm{g} / \mathrm{ml}$.

2.7.4. Measurement of reduced GSH: The concentration of glutathione in the brain cortex was measured according to the method demonstrated by Ellman (Ellman. 1959). In the tissue supernatant, $1 \mathrm{ml}$ of $4 \%$ salicylic acid was added at $4^{\circ} \mathrm{C}$ till precipitation. Then the mixture was then centrifuged at $12000 \mathrm{~g}$. After the separation of supernatant, it was mixed with $0.1 \mathrm{M}$ phosphate buffer until the appearance of yellow color. The absorbance is measured at $412 \mathrm{~nm}$ using Shimadzu spectrophotometer and the estimated values were expressed as $\mu \mathrm{mol} / \mathrm{mg}$ protein.

2.7.5. Estimation of catalase: The accumulation of catalase in the cortical zone was estimated by the method demonstrated by Sinha (Sinha. 1972) and Aebi (Aebi. 1974). To proceed with the reaction, $2.9 \mathrm{ml}$ of $10 \mathrm{mM} \mathrm{H} \mathrm{O}_{2}$ was mixed in $50 \mu \mathrm{M}$ potassium phosphate buffer and maintained the $\mathrm{pH}$ 7.4. Then 0.1 $\mathrm{ml}$ of tissue homogenate was mixed into that mixture. The decreased rate of absorbance at $240 \mathrm{~nm}$ was recorded for $3 \mathrm{~min}$. The calculated data was expressed as $\mu \mathrm{g} / \mathrm{mg}$ tissue protein.

2.7.6. Estimation of neuroinflammatory markers: The quantification of neuroinflammatory markers (TNF-a, IL-1 $\beta$, IL-6) was done by using ELISA kits. The final concentration was estimated from the standard curve for checking neuroinflammatory markers (Barksby et al. 2007).

\subsection{Neurochemical analysis:}

2.8.1. Estimation of Brain catecholamines by HPLC-ECD: Catecholamines (Nor-epinephrin, dopamine and serotonin) level was estimated by using high-performance liquid chromatography connected with an electrochemical detector. Sodium citrate buffer $(\mathrm{pH} 4.5)$ and acetonitrile with a ratio of 87:13 (v/v) were used for preparing the mobile phase. Sodium citrate buffer was prepared with $10 \mathrm{mM}$ citric acid, $25 \mathrm{mM}$ $\mathrm{NaH}_{2} \mathrm{HPO}_{4}, 25 \mathrm{mM}$ EDTA, and $2 \mathrm{mM}$ of 1-heptane sulfonic acid. For the uninterrupted separation, the separation rate was maintained with a flow rate of $0.8 \mathrm{ml} / \mathrm{min}$. At the injector point, a total $20 \mu \mathrm{l}$ of the 
sample was injected after being filtrated through a $0.2 \mathrm{~nm}$ nylon filter (Patel et al. 2005). On the 15th day, the brain samples were cut and $0.2 \mathrm{M}$ perchloric acid was used for the homogenization of brain samples. Then the samples were centrifuged for 5 minutes at $12000 \mathrm{~g}$. The supernatant was filtered and injected. Breeze software was used for the recording of the plotted graph and the concentrations of neurotransmitters levels were calculated from the standard curve (Jamwal et al. 2015).

2.8.2. GABA and Glutamate estimation by HPLC-ECD: The levels of GABA and Glutamate were estimated according to the method described by Donzanti and Yamamoto et al (Donzanti and Yamamoto. 1988). $100 \mathrm{mM} \mathrm{Na}_{2} \mathrm{HPO}_{4}, 25 \mathrm{mM}$ EDTA and $22 \%$ methanol ( $\mathrm{pH}$ 6.5) were used for the preparation of the mobile phase. For the uninterrupted separation, the flow rate was maintained at $1.2 \mathrm{ml} / \mathrm{min}$. Total $20 \mu \mathrm{l}$ of the samples were injected through rheodyne valve injector. $0.2 \mathrm{M}$ perchloric acid was used for the homogenization of the brain tissues. Then the centrifugation of brain samples was done for 15 minutes at $12,000 \mathrm{~g}$. Derivatization of supernatant was done using OPA/-ME and before injecting the sample, the samples were being filtered through nylon filters $(0.22 \mathrm{~mm})$. Recorded data were analyzed with the help of breeze software (Mark et al. 2004).

2.8.3. Pre-column derivatization procedure: Before injecting in the HPLC, the solution was derivatized with OPA/ $\beta$-ME according to the method demonstrated by Donzanti and Yamamoto(Donzanti and Yamamoto. 1988). The derivatization stock solution was made by dissolving $27 \mathrm{mg}$ of OPA in $1 \mathrm{ml}$ of methanol. Then in the solution, $5 \mathrm{ml}$ of $\beta$-ME was mixed with $9 \mathrm{ml}$ of tetraborate buffer ( $0.1 \mathrm{M}$ sodium tetraborate) at a $\mathrm{pH}$ of 10.3. The solution was kept stable in dark conditions up to 5 days. OPA/ $\beta$-ME stock solution ( $5 \mathrm{ml})$ was mixed with tetraborate buffer $(7.5 \mathrm{ml})$ for the preparation of the working solution of OPA/ $\beta$-ME. Before experiments, the solution must be prepared freshly. The brain tissue samples and the derivatized reagents were mixed with a ratio of 1:1.5, respectively (Kumar and Kumar. 2017; Singh and Kumar. 2018).

\subsection{Histological Examination:}

After isolating the brain, the brain samples were individually cut with a microtome (Leica RM 2025; Nassloch, Germany) with a thickness of $5 \mu \mathrm{m}$. The sections were fixed by immersing in $10 \%$ buffered formalin, then dehydrated in alcohol and embedded in paraffin. Two different sections were examined for individual brain samples (cortex and hippocampus). The samples were then stained with hematoxylin and eosin (H\&E) for assessing histopathological changes under a blindfold condition with standard microscopy.

\subsubsection{Immunohistochemical procedures:}

For the collection of lesioned cortices, coronal sections with a thickness of $4 \mu \mathrm{m}$ were cut from the bregma region (1.0-3.0 mm). For IHC staining, formalin-fixed paraffin-embedded sections $(4 \mathrm{~mm})$ were prepared. The sections were then transferred through xylene for half an hour for deparaffinization and then slides were rehydrated with absolute alcohol $95 \%, 70 \%$, and $50 \%$ in decreasing order. The endogenous peroxide activity was blocked by adding $3 \% \mathrm{H}_{2} \mathrm{O}_{2}$ in distilled water for 30 minutes, followed by tap water washing for 30 minutes. The sections were then incubated with blocking buffer ( $5 \%$ goat serum in PBS) for 30 minutes to inhibit the non-specific binding of antibodies. Then tris buffer solution 
( $\mathrm{pH}$ 7.4) was used for rinsing coronal sections for 10 minutes. Then sections were incubated with Nrf2 (1:100, ELK Biotechnology) and NFkB (1:100, ELK Biotechnology) for 1 hour. Then slides were washed with PBS for $5 \mathrm{~min}$, followed by incubation with secondary antibodies (1:500, ELK Biotechnology) for 1 hour. Again, tris buffer solution ( $\mathrm{pH}$ 7.4) was used for rinsing coronal sections for 10 minutes. The sections were then incubated with the substrate (3,3'-diaminobenzidine, DAB) and examined for colour change to brown, appeared within $10 \mathrm{~min}$ and then counterstained with hematoxylin. In immunochemical staining, the numbers of immune-positive stained cells were counted under light microscopy with a magnification of $x 400$ under blindfold conditions.

\subsection{Statistical analysis}

The data obtained of all results were represented as mean \pm standard deviation (SD) and analysed using GraphPad Prism 5.0. Two-way analysis of variance (ANOVA) followed by Bonferroni post hoc test for multiple comparisons was used for analysing behavioral parameters. Whereas, one-way analysis of variance (ANOVA) followed by Tukey post-hoc test for comparison was used for analysing biochemical, neurotransmitter, and neuroinflammatory markers. $P<0.05$ was considered as statistically significant.

\section{Result}

3.1.1. Effect of combination treatment of AKBA and piperine on grip strength performance in $\mathrm{TBI}$ rat model

The grip strength of rats was significantly reduced in the TBI control group as compared with the normal group. AKBA (25 mg/ $\mathrm{kg}$ ) and AKBA (50 mg/kg) significantly increased grip strength as compared with the TBI control group. Furthermore, AKBA $(25 \mathrm{mg} / \mathrm{kg})$ in combination with piperine $(2.5 \mathrm{mg} / \mathrm{kg})$, significantly enhanced grip strength as compared with the TBI control group, piperine per se, and AKBA treatment group and restored toward normal (Fig 2).

3.1.2. Effect of combination treatment of AKBA and piperine on rotarod test in TBI rat model

TBI control group showed a significant decrease in motor co-ordination (rotarod activity) as compared with the normal group. The rotarod activity in AKBA (25 mg/ $\mathrm{kg}$ ) and AKBA (50 mg/kg) group was significantly increased as compared with TBI control group. AKBA $(25 \mathrm{mg} / \mathrm{kg})$ in combination with piperine $(2.5 \mathrm{mg} / \mathrm{kg})$ significantly increased the rotarod activity as compared with the TBI control, piperine per se, and AKBA treatment group (Fig 3).

3.1.3. Effect of combination treatment of AKBA and piperine on open field task in TBI induced experimental rats

In the open fields task, line crossing, grooming and rearing behaviour was measured. In the TBI-induced rat group, the task activity was gradually decreased as compared with the normal group. The line crossing activity was significantly increased in AKBA ( $25 \mathrm{mg} / \mathrm{kg})$ and AKBA (50 mg/kg) treated group as compared with the TBI control group. However, the combination of AKBA $(25 \mathrm{mg} / \mathrm{kg})$ with piperine (2.5 
$\mathrm{mg} / \mathrm{kg}$ ) significantly increased the line crossing as compared with the TBI control group, piperine per se, and AKBA treatment group (Fig 4a).

After TBI, the numbers of grooming (Fig 4b) and rearing (Fig 4c) were significantly decreased in TBIinduced rat group as compared with the normal group. On the day 7 , AKBA $(25 \mathrm{mg} / \mathrm{kg}$ and $50 \mathrm{mg} / \mathrm{kg}$ ) alone and the combination group showed significant improvement in rearing while on day 14 , all treatment groups restored altered counts as compared with TBI induced rat group. In piperine treated animals, the rearing and grooming activity on day 7 as well as day 14 were significantly improved $(p<0.05$ and 0.01 , respectively).

3.1.4. Effect of combination treatment of AKBA and piperine on narrow beam task performance (time taken to cross the beam and no. of foot slips) in TBI induced experimental rats

TBI induced rats showed an increase in the time taken to cross the beam pathway and numbers of foot slip as compared with the normal group. Treatment with AKBA $(25 \mathrm{mg} / \mathrm{kg})$ and AKBA $(50 \mathrm{mg} / \mathrm{kg})$ both significantly and dose-dependently decreased reach time and foot slips as compared to the TBI control group. Among all treatment groups, AKBA $(25 \mathrm{mg} / \mathrm{kg})$ and piperine $(2.5 \mathrm{mg} / \mathrm{kg})$ combination group at day 14 was more effective in improving narrow beam walk activity (Fig $5 a$ and $5 b$ ).

3.1.5. Effect of combination treatment of AKBA and piperine on ELT and TSTQ in MWM TBI induced experimental rats

The TBI control group had taken more time in ELT to find out the hidden platform as compared with the normal group which clearly indicates deterioration in learning performance $(p<0.001)$. Both doses of AKBA ( $25 \mathrm{mg} / \mathrm{kg}$ and $50 \mathrm{mg} / \mathrm{kg}$ ) significantly improved in learning performance on day 7 whereas, at day 14 , both doses of AKBA more significantly improved than day 7. However, combination with AKBA (25 $\mathrm{mg} / \mathrm{kg})$ and piperine $(2.5 \mathrm{mg} / \mathrm{kg})$ significantly decreased the escape latency and intensified the TSTQ than TBI control group, piperine per se and AKBA ( $25 \& 50 \mathrm{mg} / \mathrm{kg}$ ), which indicating memory performance retention (Fig 6a and 6b).

\subsection{Biochemical parameters estimation}

3.2.1. Effect of combination treatment of AKBA and piperine on brain oxidative stress parameters (LPO, nitrite, reduced GSH, catalase) in TBI induced experimental rats

The levels of LPO and nitrite were elevated significantly $(p<0.001)$, whereas GSH and catalase levels were significantly reduced $(p<0.001)$ in TBI induced rats as compared with the normal group. However, AKBA $(25 \mathrm{mg} / \mathrm{kg}$ and $50 \mathrm{mg} / \mathrm{kg})$ treatment group significantly alleviated $(\mathrm{p}<0.001)$ the level of LPO and nitrite, and the levels of GSH and catalase were significantly increased as compared with TBI induced rat group. Whereas, the combination treatment group (AKBA + piperine) significantly decreased $(p<0.001)$ LPO and nitrite level and increased GSH and catalase level significantly $(p<0.001)$ as compared to the TBI control group and AKBA high dose (50 mg/kg) group (Table 2). 


\subsection{Neuroinflammatory markers}

3.3.1. Effect of combination treatment of AKBA and piperine on neuroinflammatory cytokines levels (TNFa, IL-1 $\beta$, IL-6)) in TBI induced experimental rats

The biochemical result revealed that neuroinflammatory level was changed after $\mathrm{TBI}$, presented by an elevation of IL-1 $\beta(p<0.001)$, TNF- $\alpha(p<0.001)$ and IL- $6(p<0.001)$ as compared with the normal group. The elevated levels of IL-1 $\beta$, TNF- $a$, and IL- 6 was decreased significantly $(p<0.001)$ after administration of AKBA (25 mg/kg and $50 \mathrm{mg} / \mathrm{kg})$. However, combination group of AKBA (25 mg/kg) and piperine (2.5 $\mathrm{mg} / \mathrm{kg}$ ) significantly alleviated $(\mathrm{p}<0.001)$ the level of IL-1 3 , TNF- $a$, and IL- 6 as compared with TBI induced group, piperine per se and $50 \mathrm{mg} / \mathrm{kg}$ of AKBA treated group (Fig 7).

\subsection{Neurochemical estimation}

3.4.1. Effect of combination treatment of AKBA and piperine on catecholamine levels (DA, NE, 5-HT) in TBI induced experimental rats

In the brain, dopamine is metabolized by monoamine oxidase with two intermediates, 3,4dihydroxyphenylacetic acid (DOPAC) and homovanillic acid (HVA). In comparison to the normal group, the level of catecholamines was significantly reduced $(p<0.001)$ in the TBI control group. The treatment with AKBA $25 \mathrm{mg} / \mathrm{kg}$ and AKBA $50 \mathrm{mg} / \mathrm{kg}$, significantly improved $(p<0.001)$ the level of dopamine, norepinephrine, and serotonin. Also, the combination group of AKBA $(25 \mathrm{mg} / \mathrm{kg})$ and piperine $(2.5 \mathrm{mg} / \mathrm{kg})$ significantly restored $(p<0.001)$ the level of catecholamines as compared to the TBI control group and AKBA $50 \mathrm{mg} / \mathrm{kg}$ treatment group. Further TBl-induced rats results in significant increase in the level of DOPAC and HVA. Rats treated with AKBA $(25 \mathrm{mg} / \mathrm{kg}$ and $50 \mathrm{mg} / \mathrm{kg})$ showed significantly decreased levels of DOPAC and HVA in comparison to TBI induced rats. However, the combination of AKBA (25 $\mathrm{mg} / \mathrm{kg}$ ) and piperine $(2.5 \mathrm{mg} / \mathrm{kg})$ significantly inhibited the increased levels of catecholamine metabolites as compared to the TBI induced rats (Table 3 ).

3.4.2. Effect of combination treatment of AKBA and piperine on GABA and glutamate levels in $T B I$ induced experimental rats

TBI control group revealed that the level of GABA (cortical) was significantly decreased $(p<0.001)$ as compared with the normal group. The treatment groups with AKBA $(25 \mathrm{mg} / \mathrm{kg}$ and $50 \mathrm{mg} / \mathrm{kg})$ prevented the GABA level alteration significantly $(p<0.001)$ as compared with the TBI induced rats. Whereas, the combination group with AKBA $(25 \mathrm{mg} / \mathrm{kg})$ and piperine $(2.5 \mathrm{mg} / \mathrm{kg})$ more significantly improved the altered level of GABA as compared to TBI group and AKBA high dose.

In the TBI control group, there was significant elevation $(p<0.001)$ in the level of glutamate as compared with the normal group. Treatment with AKBA $(25 \mathrm{mg} / \mathrm{kg}$ and $50 \mathrm{mg} / \mathrm{kg})$ significantly decreased $(\mathrm{p}<0.001)$ the altered level of glutamate as compared with the TBI induced group. Moreover, AKBA $(25 \mathrm{mg} / \mathrm{kg})$ and piperine $(2.5 \mathrm{mg} / \mathrm{kg})$ combination group significantly decreased $(p<0.001)$ the level of glutamate as compared to the high dose of AKBA and TBI control group (Table 4). 


\subsection{Histopathological and immunohistological results}

3.5.1. Effect of combination treatment of AKBA and piperine on neuronal loss in the cerebral cortex and hippocampal CA1 regions

Based on the results shown in hippocampal CA1 regions (figure 8A) and (cerebral cortex (CC) (figure 8B), the morphological status after TBI was examined by hematoxylin and eosin (H\&E) staining. TBI control group was found to have smaller number of intact neurons in the cerebral cortex and hippocampal CA1 regions as compared to normal group rats indicating neuronal loss. $25 \mathrm{mg} / \mathrm{kg}$ and $50 \mathrm{mg} / \mathrm{kg}$ of AKBA treatments on traumatic rats significantly protected the $\mathrm{CC}$ and $\mathrm{CA} 1$ regions from neuronal loss as compared with TBI-induced rats. Moreover, the combination treatment of AKBA with piperine markedly showed protection from decline neuron numbers as compared with the TBI control group and High dose of AKBA group.

3.5.2. Effect of combination treatment of AKBA and piperine in increasing Nrf2 and NFkB positive cells in the cortical regions

As shown in figure 9, the normal rats did not have the expression of Nrf2 positive cells in the nucleus. The TBI control group enhanced Nrf2 expression in the nucleus as compared with normal rats. AKBA (25 $\mathrm{mg} / \mathrm{kg}$ and $50 \mathrm{mg} / \mathrm{kg}$ ) treatment significantly enhanced Nrf2 positive cell expressions $(p<0.01)$. Moreover, the combination group with AKBA and piperine more significantly increased the Nrf2 positive cell expressions $(p<0.001)$ which indicates the ability of AKBA to promote Nrf2 translocation from cytoplasm to nucleus and thereby initiate the biding to the downstream genes. cells (Fig 9).

Elevation of NFkB positive cell expressions was found significantly higher in the TBI control group as compared to the normal group ( $\mathrm{p}<0.001)$. AKBA $(25 \mathrm{mg} / \mathrm{kg}$ and $50 \mathrm{mg} / \mathrm{kg}$ ) treatment to the TBI induced group, significantly lowered the NFkB positive cells as compared with the TBI control group $(p<0.05$, $p<0.01$, respectively). Moreover, simultaneous administration of AKBA and piperine significantly reduced the generation of NFkB positive cell expressions as compared with TBI control and AKBA high dose treatment group. (Fig 10).

\section{Discussion}

The present study result showed that the potential protective effect of AKBA in combination with piperine against lateral fluid percussion induced TBI in experimental rats. The lateral fluid percussion injury (LFPI) model is the most utilized model because it shows construct validity whereas it successfully recreates etiological outcomes of human TBI. The basic principle of LFPI is to induce fluid pressure over the exposed skull. Traumatic brain injury causes motor coordination impairment in animals as well as in human beings (Walker and Pickett. 2007). Several available data represent the behavioural alteration in rats and humans after TBI (Dixon et al. ; Lim et al. 2013). The current investigation on gripping activity, open field task, beam crossing task, Morris water maze, and rotarod activity have shown a significant impairment in motor function and cognition after experimental TBI. The AKBA ( $25 \mathrm{mg} / \mathrm{kg})$, AKBA (50 
$\mathrm{mg} / \mathrm{kg})$ and combination of AKBA $(25 \mathrm{mg} / \mathrm{kg})$ and piperine $(2.5 \mathrm{mg} / \mathrm{kg})$ have also shown significant restoration in altered motor function. Wei et al. showed that there was an improvement in cognition in APPswe/PS1dE9 mice after treatment with AKBA (Wei et al. 2020).

There are some impairments in cognition as well as in motor functions that are observed in the early stage post -TBI and which may persist up to several years after TBI (Binder and Pankratz. 1987; Miotto et al. 2010). Draper et al. showed in their study that learning behaviour is altered both in animals and humans after TBI (Draper and Ponsford. 2008). Cortical as well as the hippocampal area is important for learning and memory processing (Pavlides et al. 1993) and which is disrupted post-TBI. The current study showed that AKBA along with piperine significantly improved memory deficits or cognitive impairments in traumatic rats.

Post TBI brain causes activation of microglial and astroglia cells, also activation of inflammatory mediators within the brain. Microglia has a role in increasing proinflammatory cytokines.

Neuroinflammation-induced secondary injury in the post-TBI patients has been associated with serious neurodegenerative diseases. Neuroinflammation may have some benefits as well as detrimental roles after TBI. Various reports have been published for the confirmation of enhancement of oxidative stress post brain injury (Jomova et al. 2010; Kaur et al. 2021; Tyurin et al. 2000). In the current experimental study, we have also noticed that the elevation of oxidative stress markers in TBI-induced rats as compared with the normal group. An increase in oxidative stress is also linked with the increase in neuroinflammatory markers including IL-6, TNF-a, IL-1 $\beta$. Also, upregulation of inflammatory responses increased NADPH oxidase enzyme. Ahmed et al. observed that in a study of oxygen-glucose deprivation/reperfusion model of bEND.3 cells, the treatment with AKBA significantly reduced the level of oxidative stress in the endothelial cells (Ahmad et al. 2019). In this current study, we have investigated that there was increased inflammation at the cortical region (increased LPO and decreased GSH and CAT). $25 \mathrm{mg} / \mathrm{kg}$ and $50 \mathrm{mg} / \mathrm{kg}$ of AKBA groups and combination group (AKBA and piperine) revealed that there was a reduction in the oxidative stress and neuroinflammation in AKBA treated group rats as compared with the TBI control group, which consider the beneficial effect of AKBA. Roy et al. have shown a significant reduction of malondialdehyde level and elevation of GSH level after the administration of AKBA treatment (Roy et al. 2020).

The increased level of inflammatory cytokines is linked with increased production of quinolinic acid and an elevated level of quinolinic acid is also linked to increased excitatory neurotransmitters (glutamate). In the synaptic cleft, the excess level of glutamate also causes neurodegeneration. After TBI, in the hippocampal region, there is an activation of extra-synaptic NR2B-containing NMDARs. The imbalance in the excitatory and inhibitory neurotransmitters shows neuronal dysfunction because of increased glutamate release, faulty reuptakes. So, the level of GABA and glutamate are altered following TBI (Ahmad et al. 2019). In our current investigation on the neurotransmitter level, we have analysed that after administration of AKBA alone and also in combination with piperine, there was a significant improvement in the altered level of GABA and glutamate levels. Catecholamines such as dopamine, norepinephrin, and serotonin also have a role to maintain normal brain physiology. So, we have checked the 
level of these catecholamines. In the present study, after induction of TBI in the experimental rats, there was a significant decrease levels of DA, NE and 5-HT in the TBI control rats as compared to normal rats. Piperine (bio enhancer) in combination with AKBA significantly restored the levels of catecholamines. Kawa et al. reported that the level of catecholamines was also impaired after the induction of TBI in rats (Kawa et al. 2015). Several reports have demonstrated that there was an altered level of catecholamines in the neurodegenerative diseases (Barksby et al. 2007; Chen et al. 2017).

Post-TBI brain shows major histopathological changes which lead to behavioural alteration and cognitive deficits (Girgis et al. 2016). In the current study, we have performed the histopathological analysis to find the structural and molecular changes after TBI. In the TBI control groups, there were decreased numbers of intact neurons in both hippocampal and cortical regions after 2 weeks of TBI induction. Piperine along with AKBA more significantly increased the counts of intact neurons and causes neurogenesis more profoundly.

AKBA is known to be an Nrf2 activator that shows a protective defence mechanism through $\mathrm{HO}-1$ neuroprotective pathway. Nrf2 is an antioxidant defence mechanism regulator (Hartmann et al. 2012). In a basal condition, Nrf2 resides in the cytoplasm along with Kelch-like ECH associated protein 1 (Keap1). Nuclear gathering of Nrf2 upregulates endogenous antioxidant mechanisms (Wang. 2001). One study suggested that AKBA has a role in the translocation of cytoplasmic Nrf2 to the nucleus (Alfieri et al. 2013). Another useful study demonstrated that stimulation of Nrf2 expression by triterpenoid could alleviate MPTP-induced oxidative stress in the mice model whereas Nrf2 knockout mice were unable to show protection in MPTP induced neurotoxicity (Ding et al. 2014). In our study, we have also observed the translocations of cytoplasmic Nrf2 to the nuclear region of the cortex under oxidative stress. The expression of Nrf2 positive cells (binding of AKBA to Nrf2) was markedly increased in the combination group of AKBA and piperine as compared to the TBI control group, AKBA alone groups. On the other side, in normal conditions, nuclear factor kappa B (NFkB) remains in the cytoplasm but upon activation, translocate to the nucleus. NFkB is linked with various human diseases like Parkinson's, Alzheimer's disease, atherosclerosis (Serasanambati and Chilakapati. 2016). The activated level of NFkB is increased following TBI and resides for a prolonged time (NONAKA et al. 1999). One study revealed that upon AKBA administration, the elevated level of NFkB was prevented in experimental mice (Morgese et al. 2021). The cells showed a high level of NFkB expression in the cortical region following TBI. Piperine alone with AKBA treatment showed a significant decreased in the counts of NFkB positive cells in the cortical regions as compared with the TBI control group. In addition, more experiments using TUNNEL assay and western blotting are to be proposed in the future.

\section{Conclusion}

on concluding remarks, the current research demonstrates that treatment with $25 \mathrm{mg} / \mathrm{kg}$ and $50 \mathrm{mg} / \mathrm{kg}$ of AKBA orally and $25 \mathrm{mg} / \mathrm{kg}$ AKBA combination with piperine $(2.5 \mathrm{mg} / \mathrm{kg}$, p.o.) had significantly improved the LFPI induced behavioural, biochemical, neurotransmitter level alteration. The neuroprotective effect of AKBA in combination with piperine revitalizes its inhibitory nature towards oxidation, anti-inflammatory 
effect, and modulatory effect in catecholamines level in the cortical regions. However, it can be concluded that AKBA in combination with piperine could be a promising therapeutic intervention in traumatic brain insult.

\section{Abbreviations}

TBI, Traumatic brain injury; FPI, Fluid percussion model; AKBA, 3-acetyl-11-keto- $\beta$-boswellic acid; Nrf2, Nuclear factor-erythroid 2-related factor 2; NFkB, Nuclear factor kappa B;

\section{Declarations}

Ethical Approval and Consent to Participate (Applicable if animals/human or cell lines are used): The study was approved by IAEC meeting with protocol number ISFCP/IAEC/CPCSEA/Meeting No:28/2020/Protocol 474.

Human and Animal Rights Participate (Applicable if animals/human are used): Yes, approval statement given for use of animals

\section{Format for Availability of Data and Materials}

As per Journal policy, we will share on request.

\section{Format for Consent for Publication}

All the authors agreed to submit paper.

\section{Funding}

The authors received no financial support for the research, authorship, and/or publication of this article.

\section{Conflict of Interest}

The authors declare no conflict of interest, financial or otherwise.

\section{Acknowledgments}

The authors express their gratitude to Chairman, Mr. Parveen Garg and Director, Dr. G.D. Gupta, ISF College of Pharmacy, Moga (Punjab), India, for their excellent vision and support.

Authors Contribution: Satyabrata Kundu: Literature survey, Data collection, manuscript writing, preliminary reading; Shamsher Singh: Study Concept, Data analysis, Final reading and approval.

\section{References}

1. Aebi, H. (1974). Catalase, Methods of enzymatic analysis. Elsevier, pp. 673-684 
2. Ahmad, S., Khan, S.A., Kindelin, A., Mohseni, T., Bhatia, K., Hoda, M.N., Ducruet, A.F. (2019) Acetyl-11keto- $\beta$-boswellic acid (AKBA) attenuates oxidative stress, inflammation, complement activation and cell death in brain endothelial cells following OGD/reperfusion. Neuromolecular medicine 21(4) 505516

3. Alfieri, A., Srivastava, S., Siow, R.C., Cash, D., Modo, M., Duchen, M.R., Fraser, P.A., Williams, S.C., Mann, G.E. (2013) Sulforaphane preconditioning of the Nrf2/HO-1 defense pathway protects the cerebral vasculature against blood-brain barrier disruption and neurological deficits in stroke. Free Radical Biology and Medicine 65 1012-1022

4. Anderson, K.D., Gunawan, A., Steward, O. (2005) Quantitative assessment of forelimb motor function after cervical spinal cord injury in rats: relationship to the corticospinal tract. Experimental neurology 194(1) 161-174

5. Barksby, H., Lea, S., Preshaw, P., Taylor, J. (2007) The expanding family of interleukin-1 cytokines and their role in destructive inflammatory disorders. Clinical \& Experimental Immunology 149(2) 217-225

6. Beghelli, D., Isani, G., Roncada, P., Andreani, G., Bistoni, O., Bertocchi, M., Lupidi, G., Alunno, A. (2017) Antioxidant and ex vivo immune system regulatory properties of Boswellia serrata extracts. Oxidative medicine and cellular longevity 2017

7. Binder, L.M., Pankratz, L. (1987) Neuropsychological evidence of a factitious memory complaint. Journal of Clinical and Experimental Neuropsychology 9(2) 167-171

8. Carter, R.J., Morton, J., Dunnett, S.B. (2001) Motor coordination and balance in rodents. Current protocols in neuroscience 15(1) 8.12.11-18.12. 14

9. Chen, W.-F., Wu, L., Du, Z.-R., Chen, L., Xu, A.-L., Chen, X.-H., Teng, J.-J., Wong, M.-S. (2017) Neuroprotective properties of icariin in MPTP-induced mouse model of Parkinson's disease: Involvement of PI3K/Akt and MEK/ERK signaling pathways. Phytomedicine 25 93-99

10. Cuaz-Pérolin, C., Billiet, L., Baugé, E., Copin, C., Scott-Algara, D., Genze, F., Büchele, B., Syrovets, T., Simmet, T., Rouis, M. (2008) Antiinflammatory and antiatherogenic effects of the NF-kB inhibitor acetyl-11-keto- $\beta$-boswellic acid in LPS-challenged ApoE-/- mice. Arteriosclerosis, thrombosis, and vascular biology 28(2) 272-277

11. de Vries, H.E., Witte, M., Hondius, D., Rozemuller, A.J., Drukarch, B., Hoozemans, J., van Horssen, J. (2008) Nrf2-induced antioxidant protection: a promising target to counteract ROS-mediated damage in neurodegenerative disease? Free Radical Biology and Medicine 45(10) 1375-1383

12. Ding, Y., Chen, M., Wang, M., Wang, M., Zhang, T., Park, J., Zhu, Y., Guo, C., Jia, Y., Li, Y. (2014) Neuroprotection by acetyl-11-keto- $\beta$-boswellic acid, in ischemic brain injury involves the Nrf2/HO-1 defense pathway. Scientific reports 4(1) 1-9

13. Dixon, C., Lyeth, B., Povlishock, J., Findling, R., Hamm, R. Marmarou, a, Young, HF, and Hayes, RL (1987). A fluid percussion model of experimental brain injury in the rat. J. Neurosurg 67 110-119

14. Donzanti, B.A., Yamamoto, B.K. (1988) An improved and rapid HPLC-EC method for the isocratic separation of amino acid neurotransmitters from brain tissue and microdialysis perfusates. Life sciences 43(11) 913-922 
15. Draper, K., Ponsford, J. (2008) Cognitive functioning ten years following traumatic brain injury and rehabilitation. Neuropsychology 22(5) 618

16. Ellman, G.L. (1959) Tissue sulfhydryl groups. Archives of biochemistry and biophysics 82(1) 70-77

17. Galgano, M., Toshkezi, G., Qiu, X., Russell, T., Chin, L., Zhao, L.-R. (2017) Traumatic brain injury: current treatment strategies and future endeavors. Cell transplantation 26(7) 1118-1130

18. Girgis, F., Pace, J., Sweet, J., Miller, J.P. (2016) Hippocampal neurophysiologic changes after mild traumatic brain injury and potential neuromodulation treatment approaches. Frontiers in systems neuroscience 108

19. Green, L. (1982) Wagner D a, Glogowski J, Skipper PL, Wishnok JS, Tannenbaum SR. Analysis of nitrate, nitrite, and [15 N] nitrate in biological fluids. Anal Biochem 126 131-138

20. Hartmann, R.M., Martins, M.I.M., Tieppo, J., Fillmann, H.S., Marroni, N.P. (2012) Effect of Boswellia serrata on antioxidant status in an experimental model of colitis rats induced by acetic acid. Digestive diseases and sciences 57(8) 2038-2044

21. Itoh, K., Tong, K.I., Yamamoto, M. (2004) Molecular mechanism activating Nrf2-Keap1 pathway in regulation of adaptive response to electrophiles. Free Radical Biology and Medicine 36(10) 12081213

22. Jamwal, S., Singh, S., Kaur, N., Kumar, P. (2015) Protective effect of spermidine against excitotoxic neuronal death induced by quinolinic acid in rats: possible neurotransmitters and neuroinflammatory mechanism. Neurotoxicity research 28(2) 171-184

23. Jomova, K., Vondrakova, D., Lawson, M., Valko, M. (2010) Metals, oxidative stress and neurodegenerative disorders. Molecular and cellular biochemistry 345(1) 91-104

24. Kandhare, A.D., Bodhankar, S.L., Mohan, V., Thakurdesai, P.A. (2015) Effect of glycosides based standardized fenugreek seed extract in bleomycin-induced pulmonary fibrosis in rats: decisive role of Bax, Nrf2, NF-kB, Muc5ac, TNF-a and IL-1 $\beta$. Chemico-biological interactions 237 151-165

25. Karunanithi, K., Annadurai, A., Krishnamoorthy, M., Elumalai, P., Manivasagam, T. (2011) 1-methyl 4phenyl 1, 2, 3, 6-tetrahydropyridine is a potent neurotoxin: Gamma-tocopherol recuperate behavior, dopamine, and oxidative stress on Parkinsonic mice. International Journal of Nutrition, Pharmacology, Neurological Diseases 1(2) 139

26. Kaur, A., Jaiswal, G., Brar, J., Kumar, P. (2021) Neuroprotective effect of nerolidol in traumatic brain injury associated behavioural comorbidities in rats. Toxicology Research

27. Kawa, L., Arborelius, U.P., Yoshitake, T., Kehr, J., Hökfelt, T., Risling, M., Agoston, D. (2015) Neurotransmitter systems in a mild blast traumatic brain injury model: catecholamines and serotonin. Journal of neurotrauma 32(16) 1190-1199

28. Kharatishvili, I., Nissinen, J., McIntosh, T., Pitkänen, A. (2006) A model of posttraumatic epilepsy induced by lateral fluid-percussion brain injury in rats. Neuroscience 140(2) 685-697

29. Kobayashi, M., Yamamoto, M. (2006) Nrf2-Keap1 regulation of cellular defense mechanisms against electrophiles and reactive oxygen species. Advances in enzyme regulation 46(1) 113-140 
30. Kumar, B., Kuhad, A., Chopra, K. (2011) Neuropsychopharmacological effect of sesamol in unpredictable chronic mild stress model of depression: behavioral and biochemical evidences. Psychopharmacology 214(4) 819-828

31. Kumar, M., Kumar, P. (2017) Protective effect of spermine against pentylenetetrazole kindling epilepsy induced comorbidities in mice. Neuroscience research 120 8-17

32. Langlois, J.A., Rutland-Brown, W., Wald, M.M. (2006) The epidemiology and impact of traumatic brain injury: a brief overview. The Journal of head trauma rehabilitation 21(5) 375-378

33. Lifshitz, J., Rowe, R.K., Griffiths, D.R., Evilsizor, M.N., Thomas, T.C., Adelson, P.D., Mclntosh, T.K. (2016) Clinical relevance of midline fluid percussion brain injury: acute deficits, chronic morbidities and the utility of biomarkers. Brain injury 30(11) 1293-1301

34. Lim, M.M., Elkind, J., Xiong, G., Galante, R., Zhu, J., Zhang, L., Lian, J., Rodin, J., Kuzma, N.N., Pack, A.I. (2013) Dietary therapy mitigates persistent wake deficits caused by mild traumatic brain injury. Science translational medicine 5(215) 215ra173-215ra173

35. Maneshi, M.M., Sachs, F., Hua, S.Z. (2015) A threshold shear force for calcium influx in an astrocyte model of traumatic brain injury. Journal of neurotrauma 32(13) 1020-1029

36. Mark, K.A., Soghomonian, J.-J., Yamamoto, B.K. (2004) High-dose methamphetamine acutely activates the striatonigral pathway to increase striatal glutamate and mediate long-term dopamine toxicity. Journal of Neuroscience 24(50) 11449-11456

37. McKee, A.C., Daneshvar, D.H. (2015) The neuropathology of traumatic brain injury. Handbook of clinical neurology 127 45-66

38. Miotto, E.C., Cinalli, F.Z., Serrao, V.T., Benute, G.G., Lucia, M.C.S., Scaff, M. (2010) Cognitive deficits in patients with mild to moderate traumatic brain injury. Arquivos de neuro-psiquiatria 68(6) 862-868

39. Morgese, M.G., Bove, M., Francavilla, M., Schiavone, S., Dimonte, S., Colia, A.L., Bevilacqua, M., Trabace, L., Tucci, P. (2021) Sublingual AKBA Exerts Antidepressant Effects in the A $\beta$-Treated Mouse Model. Biomolecules 11(5) 686

40. Moris, R. (1984) Developments of a water-maze procedure for studing spatial learing in the rats. $J$ Neurosci methods 11(1) 47

41. NONAKA, M., CHEN, X.-H., PIERCE, J.E., LEONI, M.J., McINTOSH, T.K., WOLF, J.A., SMITH, D.H. (1999) Prolonged activation of NF-KB following traumatic brain injury in rats. Journal of neurotrauma 16(11) 1023-1034

42. Patel, B.A., Arundell, M., Parker, K.H., Yeoman, M.S., O'Hare, D. (2005) Simple and rapid determination of serotonin and catecholamines in biological tissue using high-performance liquid chromatography with electrochemical detection. Journal of Chromatography B 818(2) 269-276

43. Pavlides, C., Miyashita, E., Asanuma, H. (1993) Projection from the sensory to the motor cortex is important in learning motor skills in the monkey. Journal of neurophysiology 70(2) 733-741

44. Roy, S., Hari, S., Banerjee, A., Kannan, R., Jothimani, G., Raghavan, V., Pathak, S. (2020) A Study on the Effects of Acetyl-11-Keto- $\beta$-Boswellic Acid Against Dextran Sodium Sulfate Induced Acute and Chronic Colitis in Swiss Albino Mice. Journal of Applied Biotechnology Reports 7(4) 224-232 
45. Serasanambati, M., Chilakapati, S.R. (2016) Function of nuclear factor kappa B (NF-kB) in human diseases-a review. South Indian Journal of Biological Sciences 2(4) 368-387

46. Singh, S., Kumar, P. (2018) Piperine in combination with quercetin halt 6-OHDA induced neurodegeneration in experimental rats: Biochemical and neurochemical evidences. Neuroscience research 133 38-47

47. Sinha, A.K. (1972) Colorimetric assay of catalase. Analytical biochemistry 47(2) 389-394

48. Takada, Y., Ichikawa, H., Badmaev, V., Aggarwal, B.B. (2006) Acetyl-11-keto- $\beta$-boswellic acid potentiates apoptosis, inhibits invasion, and abolishes osteoclastogenesis by suppressing NF-KB and NF-KB-regulated gene expression. The Journal of Immunology 176(5) 3127-3140

49. Tyurin, V.A., Tyurina, Y.Y., Borisenko, G.G., Sokolova, T.V., Ritov, V.B., Quinn, P.J., Rose, M., Kochanek, P., Graham, S.H., Kagan, V.E. (2000) Oxidative stress following traumatic brain injury in rats: quantitation of biomarkers and detection of free radical intermediates. Journal of neurochemistry 75(5) 2178-2189

50. Walker, W.C., Pickett, T.C. (2007) Motor impairment after severe traumatic brain injury: a longitudinal multicenter study. Journal of rehabilitation research and development 44(7) 975

51. Wang, B., Zhu, X., Kim, Y., Li, J., Huang, S., Saleem, S., Li, R.-C., Xu, Y., Dore, S., Cao, W. (2012) Histone deacetylase inhibition activates transcription factor Nrf2 and protects against cerebral ischemic damage. Free Radical Biology and Medicine 52(5) 928-936

52. Wang, X. (2001) The expanding role of mitochondria in apoptosis. Genes \& development 15(22) 2922-2933

53. Wei, C., Fan, J., Sun, X., Yao, J., Guo, Y., Zhou, B., Shang, Y. (2020) Acetyl-11-keto- $\beta$-boswellic acid ameliorates cognitive deficits and reduces amyloid- $\beta$ levels in APPswe/PS1dE9 mice through antioxidant and anti-inflammatory pathways. Free Radical Biology and Medicine 150 96-108

54. Wills, E. (1966) Mechanisms of lipid peroxide formation in animal tissues. Biochemical journal 99(3) 667-676

\section{Tables}


Table 1 Experimental groups of animals

\begin{tabular}{|c|c|c|c|}
\hline S. No & Groups & Animal Species & No. of animals \\
\hline 1. & Normal group & \multirow{6}{*}{ Wistar rats } & 6 \\
\hline 2. & TBI control $(50 \mathrm{mmHg})$ & & 7 \\
\hline 3. & TBI + Piperine $(2.5 \mathrm{mg} / \mathrm{kg}, \mathrm{p} . \mathrm{o})$ & & 7 \\
\hline 4. & TBI + AKBA (25 mg/kg, p.o) & & 7 \\
\hline 5. & TBI + AKBA (50 mg/kg, p.o) & & 7 \\
\hline 6. & $\begin{array}{c}\text { TBI + AKBA (25 mg/kg, p.o) + Piperine (2.5 } \\
\mathrm{mg} / \mathrm{kg}, \text { p.o })\end{array}$ & & 7 \\
\hline
\end{tabular}

Table 2 Effect of combination treatment of AKBA and piperine on brain oxidative stress parameters (LPO, nitrite, reduced GSH, catalase) in TBI induced experimental rats

\begin{tabular}{|c|c|c|c|c|}
\hline Groups & $\begin{array}{c}\text { MDA } \\
\text { (nmol/mg } \\
\text { protein) }\end{array}$ & $\begin{array}{c}\text { Nitrite level } \\
(\mu \mathrm{g} / \mathrm{mL})\end{array}$ & $\begin{array}{c}\text { GSH } \\
(\mu \mathrm{mol} / \mathrm{mg} \text { protein })\end{array}$ & $\begin{array}{c}\text { Catalase }(\mu \mathrm{g} / \mathrm{mg} \\
\text { protein) }\end{array}$ \\
\hline Control & $1.21 \pm 0.21$ & $163.49 \pm 5.81$ & $0.093 \pm 0.01$ & $17.3 \pm 0.92$ \\
\hline TBI control & $3.67 \pm 0.40^{*}$ & $363.1 \pm 7.95^{\circ}$ & $0.021 \pm 0.006^{\circ}$ & $2.94 \pm 0.34^{\circ}$ \\
\hline TBI+ piperine $2.5 \mathrm{mg} / \mathrm{kg}$ & $3.24 \pm 0.39^{\&}$ & $344.01 \pm 9.18^{\&}$ & $0.037 \pm 0.008^{\&}$ & $4.97 \pm 0.47^{\&}$ \\
\hline TBI+ AKBA 25 mg/kg & $3.00 \pm 0.19^{\&}$ & $310.45 \pm 12.92^{8}$ & $0.040 \pm 0.007^{8}$ & $6.54 \pm 0.43^{\&}$ \\
\hline TBI+ AKBA 50 mg/kg & $2.37 \pm 0.23^{\&}$ & $270.55 \pm 8.04^{\&}$ & $0.058 \pm 0.01^{\&}$ & $10.81 \pm 0.94^{\&}$ \\
\hline $\begin{array}{l}\text { TBI+ piperine+ } \\
\text { AKBA } 25 \text { mg/kg }\end{array}$ & $1.74 \pm 0.22^{\# \&}$ & $211.43 \pm 13.24^{\mathrm{FE}}$ & $0.076 \pm 0.005^{\# \&}$ & $15.06 \pm 1.05^{\# \&}$ \\
\hline
\end{tabular}


Results are expressed as the mean \pm SD and analysed by one-way analysis of variance followed by Tukey's post hoc test. ${ }^{*}<<0.001$ vs. normal, ${ }^{~} \mathrm{P}<0.001$ vs TBI control, ${ }^{*} \mathrm{p}<0.001$ vs TBI + AKBA $50 \mathrm{mg} / \mathrm{kg}$.

Table 3 Effect of combination treatment of AKBA and piperine on catecholamine levels (DA, NE, 5-HT) in TBI induced experimental rats

\begin{tabular}{|c|c|c|c|c|c|}
\hline Groups & $\begin{array}{c}\text { NE } \\
\text { (ng/mg tissue } \\
\text { protein) }\end{array}$ & $\begin{array}{c}\text { DA } \\
\text { (ng/mg tissue } \\
\text { protein) }\end{array}$ & $\begin{array}{c}\text { 5-HT } \\
\text { (ng/mg tissue } \\
\text { protein) }\end{array}$ & $\begin{array}{c}\text { HVA } \\
\text { (ng/mg tissue } \\
\text { protein) }\end{array}$ & $\begin{array}{c}\text { DOPAC } \\
\text { (ng/mg tissue } \\
\text { protein) }\end{array}$ \\
\hline Control & $60.52 \pm 5.17$ & $99.80 \pm 5.62$ & $40.3 \pm 4.13$ & $5.08 \pm 1.41$ & $7.66 \pm 1.86$ \\
\hline TBI control & $16.87 \pm 3.48^{*}$ & $19.08 \pm 4.87^{*}$ & $10.52 \pm 3.52^{*}$ & $20.71 \pm 2.28^{*}$ & $24 \pm 2^{*}$ \\
\hline $\begin{array}{c}\text { TBI+ Piperine 2.5 } \\
\text { mg/kg }\end{array}$ & $23.64 \pm 4.76^{\$}$ & $27.41 \pm 3.80^{\$}$ & $12.83 \pm 3.59^{\$}$ & $17.42 \pm 2.29^{\$}$ & $20.42 \pm 1.71^{5}$ \\
\hline TBI+AKBA 25 \\
mg/kg
\end{tabular}

Results are expressed as the mean \pm SD and analysed one-way analysis of variance followed by Tukey's post hoc test. ${ }^{*} \mathrm{P}<0.001$ vs normal, ${ }^{5} \mathrm{P}<0.05$ vs TBI control, ${ }^{\&} \mathrm{P}<0.001$ vs TBI control, \#p $<0.001 \mathrm{vs}$ TBI + AKBA $50 \mathrm{mg} / \mathrm{kg}$

Table 4 Effect of combination treatment of AKBA and piperine on GABA and glutamate levels in TBI induced experimental rats 


\begin{tabular}{|l|c|c|}
\hline \multicolumn{1}{|c|}{ Groups } & GABA (ng/mg tissue protein) & $\begin{array}{c}\text { Glutamate } \\
\text { (ng/mg tissue protein) }\end{array}$ \\
\hline Control & $58.97 \pm 7.07$ & $81.18 \pm 5.97$ \\
\hline TBI control & $15.79 \pm 4.60^{\circ}$ & $164.08 \pm 7.45^{\circ}$ \\
\hline TBI+ Piperine 2.5 mg/kg & $21.74 \pm 8.38^{5}$ & $154.91 \pm 8.99^{5}$ \\
\hline TBI+AKBA 25 mg/kg & $29.06 \pm 5.90^{\&}$ & $138.93 \pm 6.38^{\&}$ \\
\hline TBI+AKBA 50 $\mathbf{~ m g / k g ~}$ & $38.68 \pm 6.06^{\&}$ & $113.47 \pm 8.91^{\&}$ \\
\hline $\begin{array}{l}\text { TBI+ piperine + AKBA 25 } \\
\text { mg/kg }\end{array}$ & $49.59 \pm 6.01^{\& \#}$ & $99.18 \pm 7.10^{\& \#}$ \\
\hline
\end{tabular}

Results are expressed as the mean \pm SD and analysed one-way analysis of variance followed by Tukey's post hoc test. ${ }^{*} P<0.001$ vs normal, ${ }^{\$} P<0.05$ vs TBI control, ${ }^{\&} P<0.001$ vs TBI control, ${ }^{\#} p<0.001$ vs TBI + AKBA $50 \mathrm{mg} / \mathrm{kg}$

Figures 


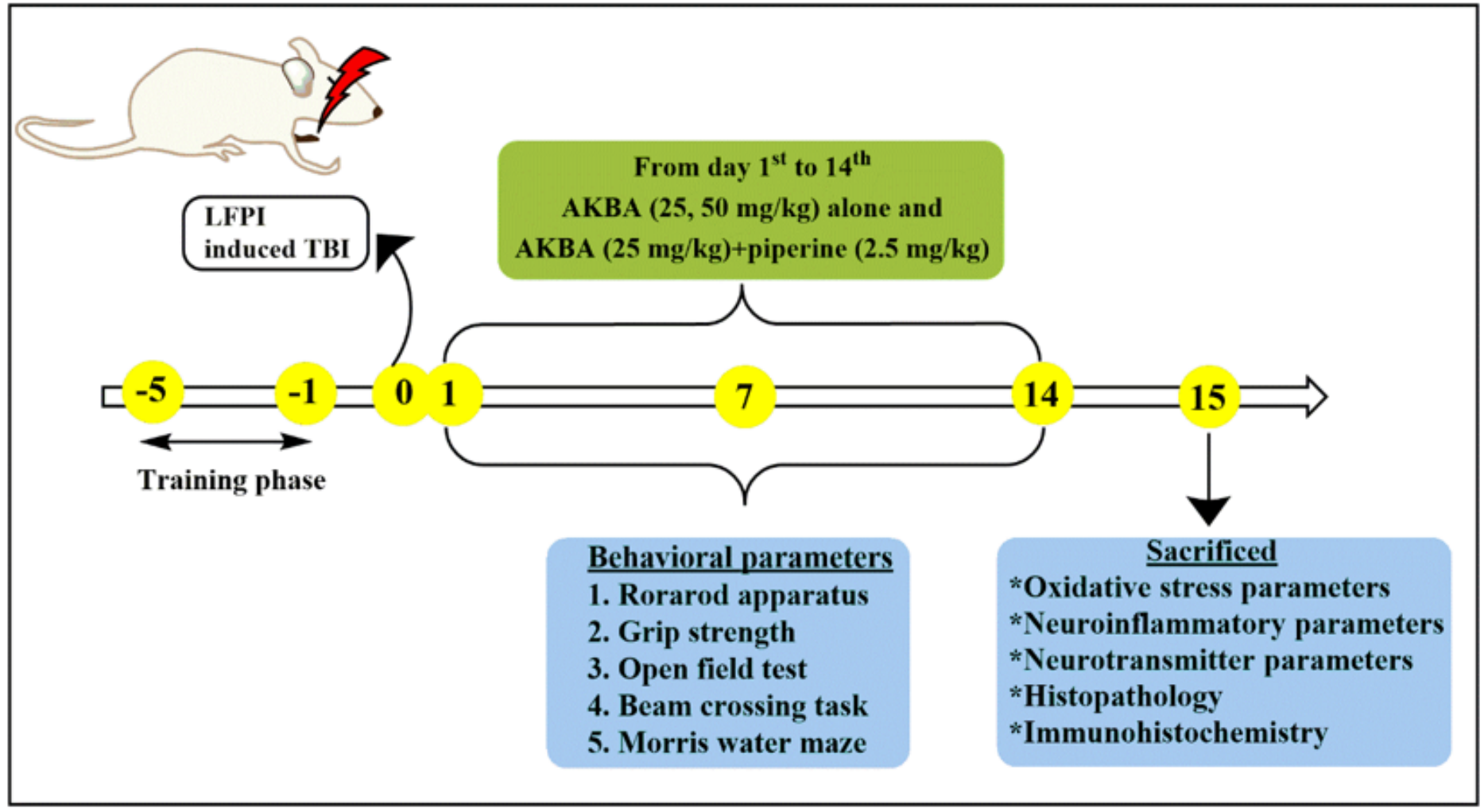

\section{Figure 1}

Figure 1

Experimental protocol 


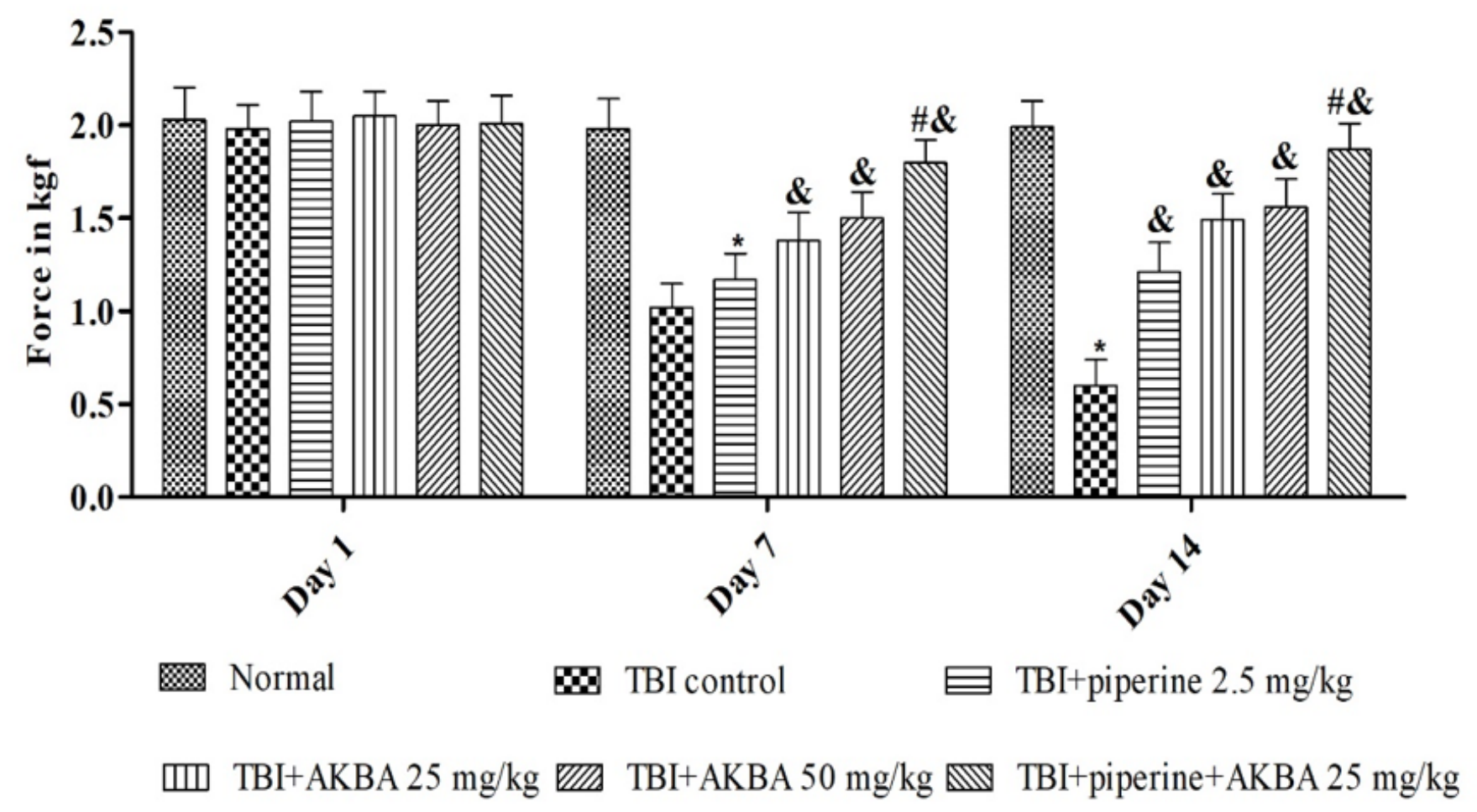

Figure 2

Figure 2

Effect of AKBA in combination with piperine on grip strength performance in TBI model of rats. Results are expressed as the mean $\pm S D$ and analysed by two-way analysis of variance followed by Bonferroni's post hoc test. ${ }^{*} P<0.001$ vs. normal, $\& P<0.001$ vs TBI control, $\# p<0.001$ vs TBI + AKBA $50 \mathrm{mg} / \mathrm{kg}$. 


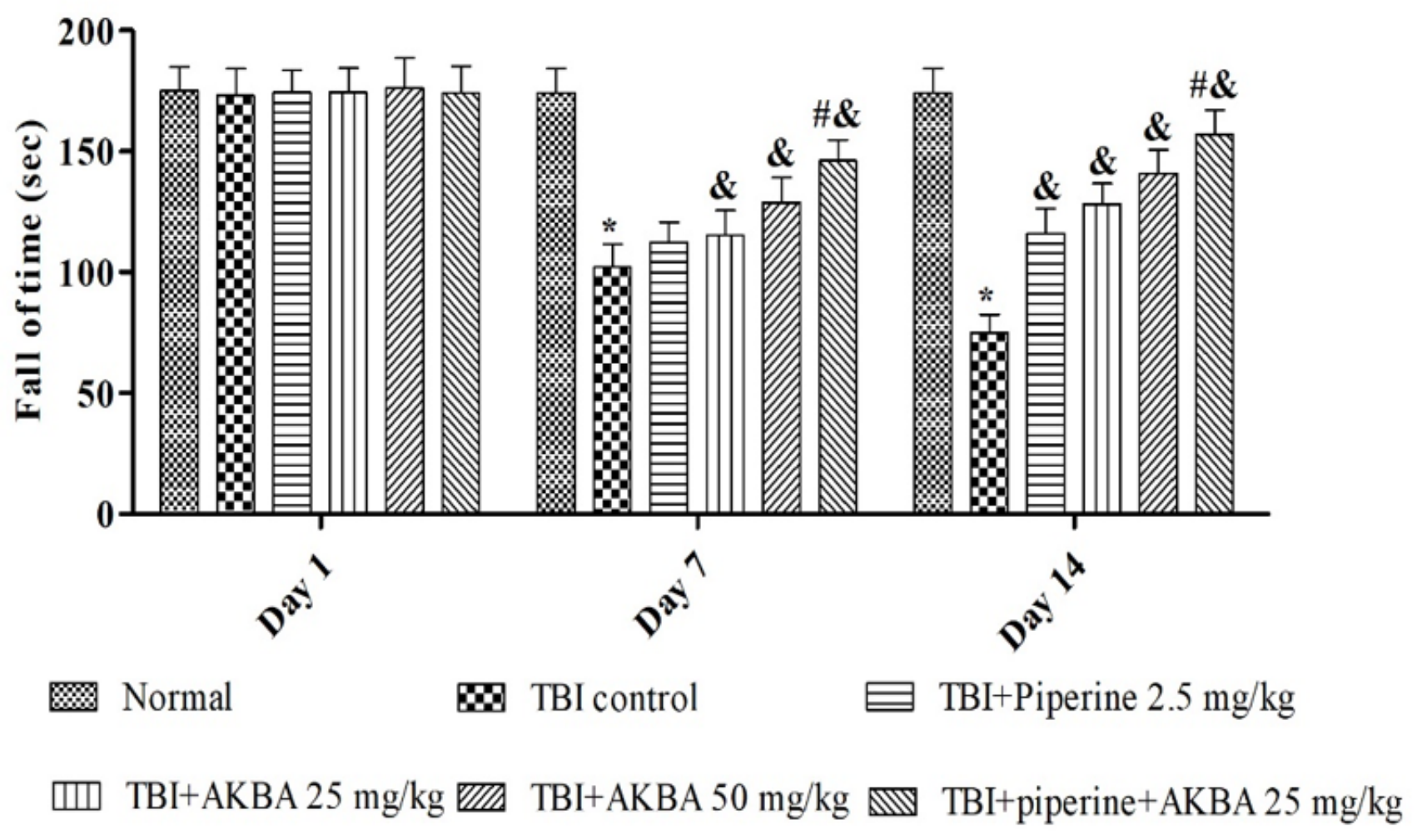

Figure 3

Figure 3

Effect of AKBA in combination with piperine on rotarod activity in TBI model of rats. Results are expressed as the mean $\pm S D$ and analysed by two-way analysis of variance followed by Bonferroni's post hoc test. ${ }^{*} P<0.001$ vs. normal, \&P<0.001 vs TBI control, $\# p<0.001$ vs TBI + AKBA $50 \mathrm{mg} / \mathrm{kg}$. 


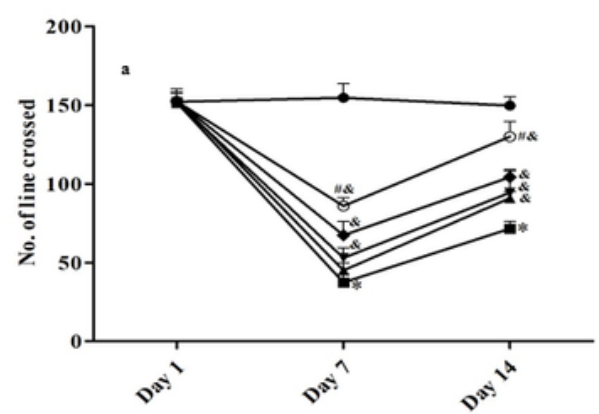

$\rightarrow$ Normal
$\rightarrow$ TBI+AKBA $25 \mathrm{mg} / \mathrm{kg} \rightarrow \mathrm{TBI}$ control $\rightarrow$ TBI+AKBA $50 \mathrm{mg} / \mathrm{kg} \rightleftharpoons \mathrm{TBI}+$ piperine $2.5 \mathrm{mg} / \mathrm{kg}$
$\rightarrow \mathrm{TBI}+$ piperine+AKBA $25 \mathrm{mg} / \mathrm{kg}$

।

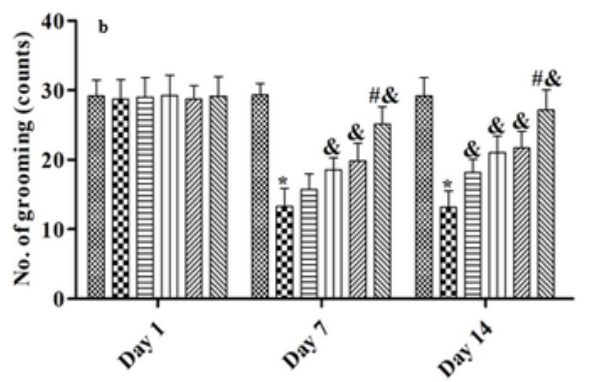

Normal $\quad \Leftrightarrow$ TBI Control $\quad \boxminus$ TBI+piperine $2.5 \mathrm{mg} / \mathrm{kg}$

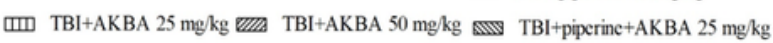

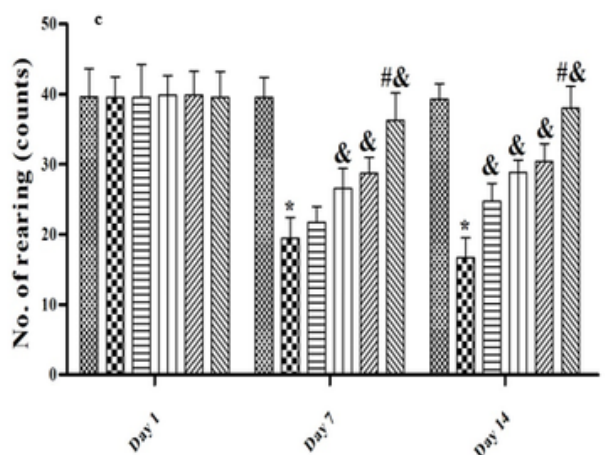

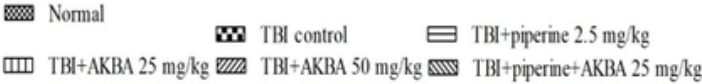

Figure 4

\section{Figure 4}

Effect of AKBA in combination with piperine on open field task in TBI model of rats- a: No. of line crossed, b: No. of grooming, c: No. of rearing. Results are expressed as the mean \pm SD and analysed by two-way analysis of variance followed by Bonferroni's post hoc test. ${ }^{*} \mathrm{P}<0.001$ vs. normal, $\& \mathrm{P}<0.001 \mathrm{vs} \mathrm{TBI}$ control, $\# p<0.001$ vs TBI + AKBA $50 \mathrm{mg} / \mathrm{kg}$. 

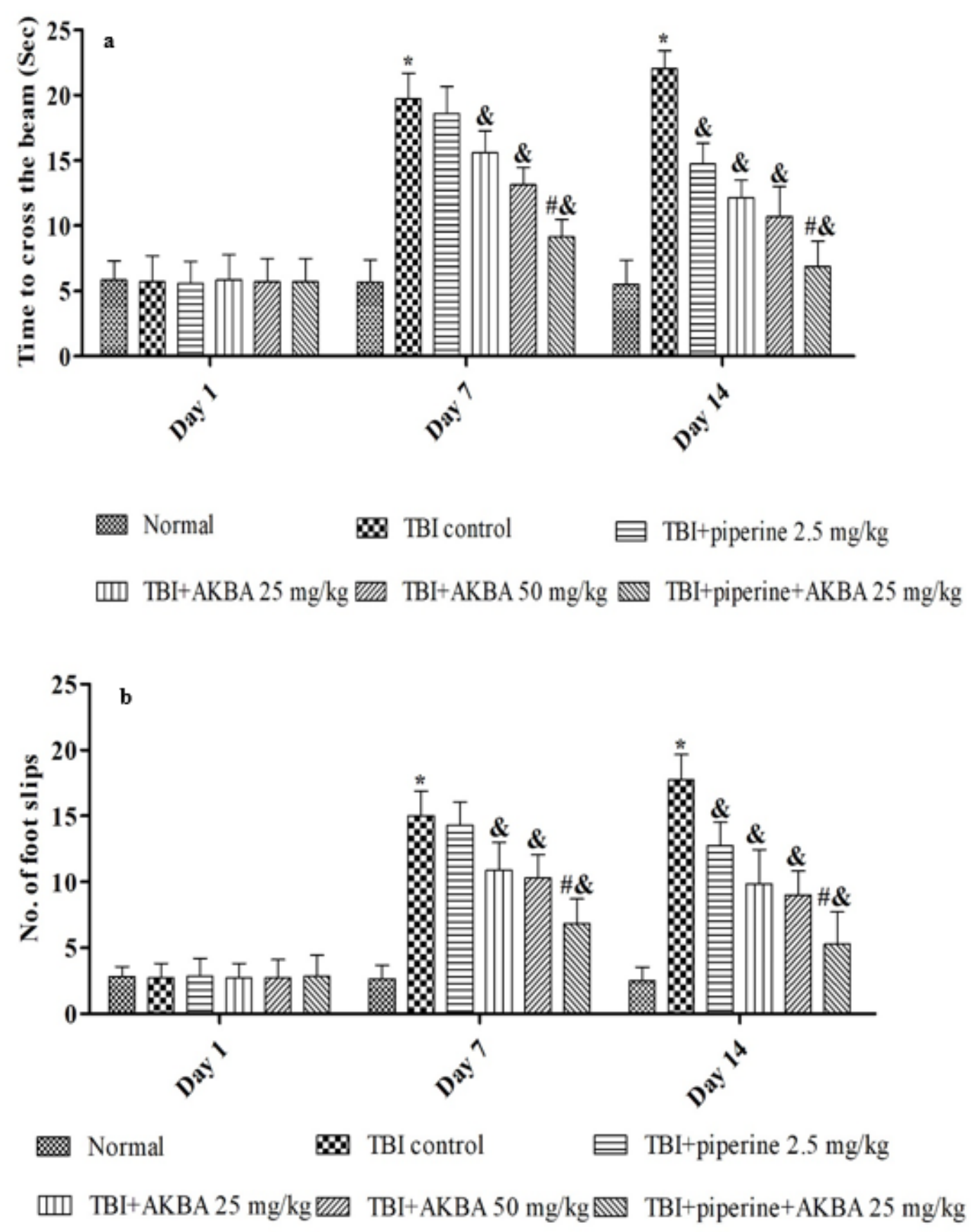

\section{Figure 5}

\section{Figure 5}

Effect of AKBA in combination with piperine on narrow beam task performance in TBI model of rats - a: Time to cross the beam (sec), b: No of foot slips. Results are expressed as the mean \pm SD and analysed by two-way analysis of variance followed by Bonferroni's post hoc test. ${ }^{*} P<0.001$ vs. normal, \&P<0.001 vs TBI normal, \#p<0.001 vs TBI + AKBA $50 \mathrm{mg} / \mathrm{kg}$. 

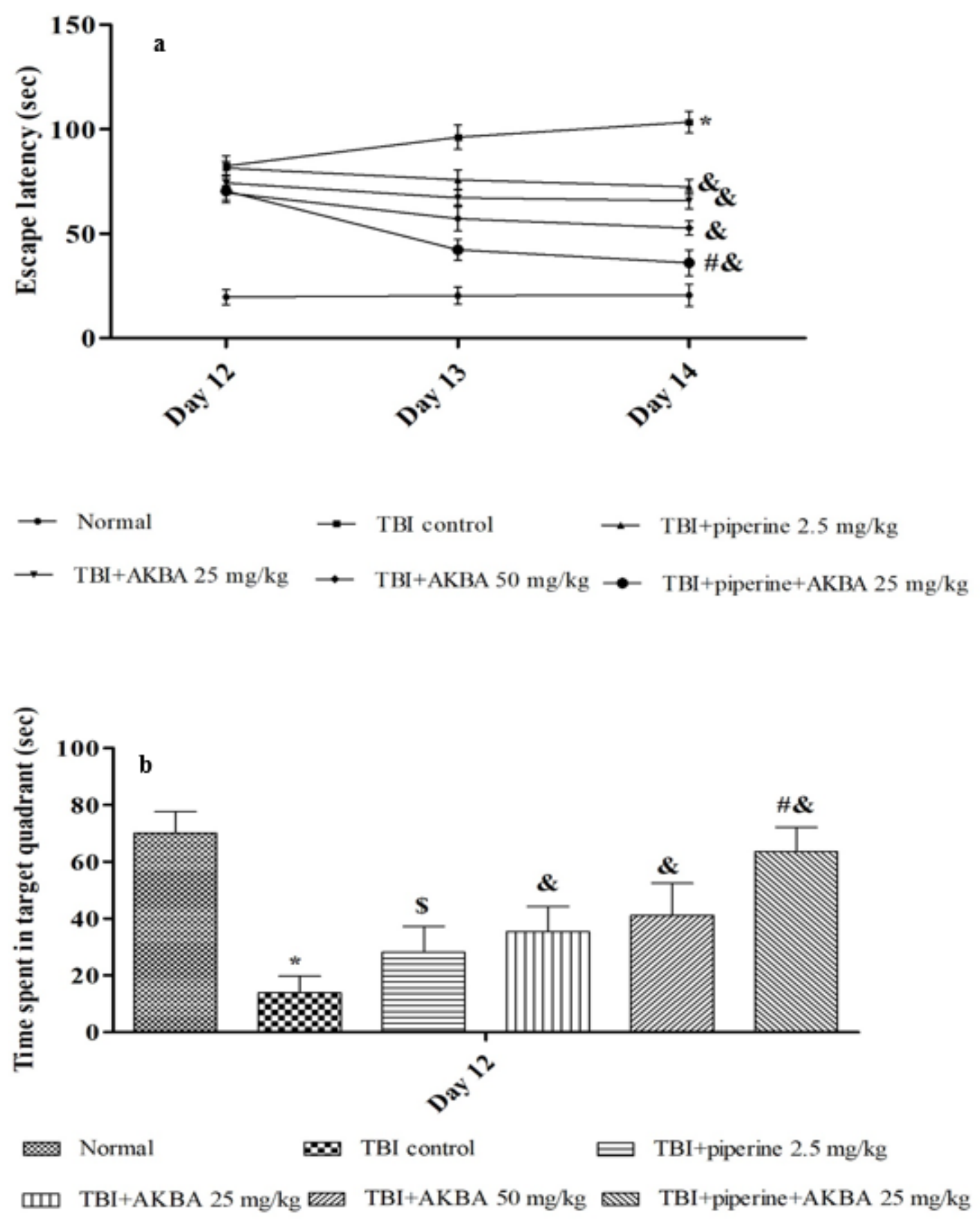

Figure 6

Figure 6

Effect of AKBA in combination with piperine in MWM- TBI model of rats- a: Escape latency, b: Time spent in target quadrant. Results are expressed as the mean \pm SD and analysed by two-way analysis of variance followed by Bonferroni's post hoc test. ${ }^{*} \mathrm{P}<0.001$ vs. normal, $\& \mathrm{P}<0.001$ vs TBI control group, $\# p<0.001 \mathrm{vs} T B I+A K B A 50 \mathrm{mg} / \mathrm{kg}$. 


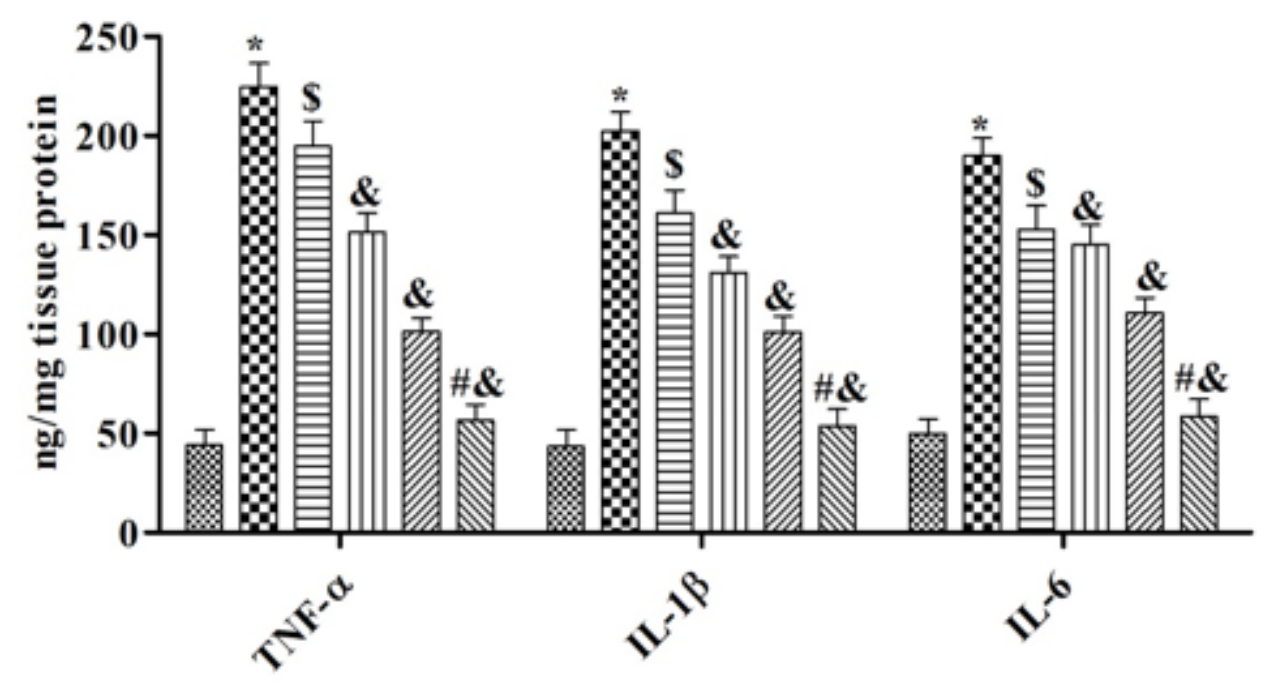
@ Control
$\$$ TBI control
$\Longrightarrow \mathrm{TBI}+$ piperine $2.5 \mathrm{mg} / \mathrm{kg}$

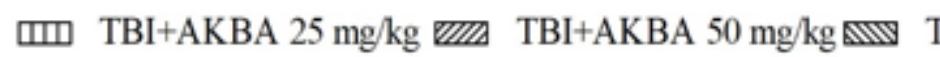
$\mathrm{TBI}+$ piperine+AKBA $25 \mathrm{mg} / \mathrm{kg}$

Figure 7

Figure 7

Effect of AKBA in combination with piperine on pro-inflammatory cytokines levels (TNF- $\alpha$, IL-1 $\beta$, IL-6) in TBI induced experimental rats. Results are expressed as the mean \pm SD and analysed by one-way analysis of variance followed by Tukey's post hoc test. ${ }^{*} \mathrm{P}<0.001$ vs. normal, $\$ \mathrm{P}<0.05$ vs TBI control, $\& \mathrm{P}<0.001$ vs TBI control, $\# p<0.001$ vs TBI + AKBA $50 \mathrm{mg} / \mathrm{kg}$.
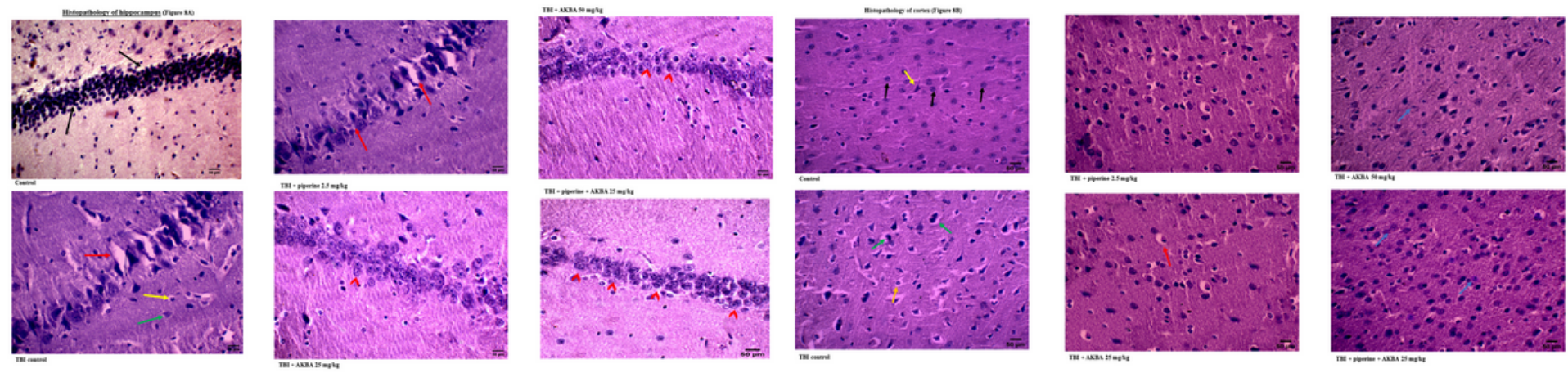

\section{Figure 8}

A. Effect of AKBA in combination with piperine on neuronal loss in hippocampal CA1 region.

Photomicrograph of hippocampus of normal rats showing normal neurons (black arrow), TBI induced rats showing vacuole containing cellular debris (red arrow), vacuolated neurocytes (yellow arrow) and abnormal Nissl granules (green arrow). AKBA treated groups showed near normal neurons (red arrow 
head). Stain: Hematoxylin and Eosin; magnification: 400 x. B. Effect of AKBA in combination with piperine on neuronal loss in cerebral cortical regions. Photomicrograph of cerebral cortex of normal rats showing normal neurons (black arrow), normal pyramidal cells (yellow arrow). TBI induced rats showing dystrophic changes in the form of shrunken hyperchromatic with chromatolysis (orange arrow) and shrunken nerve cell with dark nuclei (green arrow). Red arrow shows less vacuole formation. AKBA treated groups showed near normal neurons (blue arrow). Stain: Hematoxylin and Eosin; magnification: $400 \mathrm{x}$.
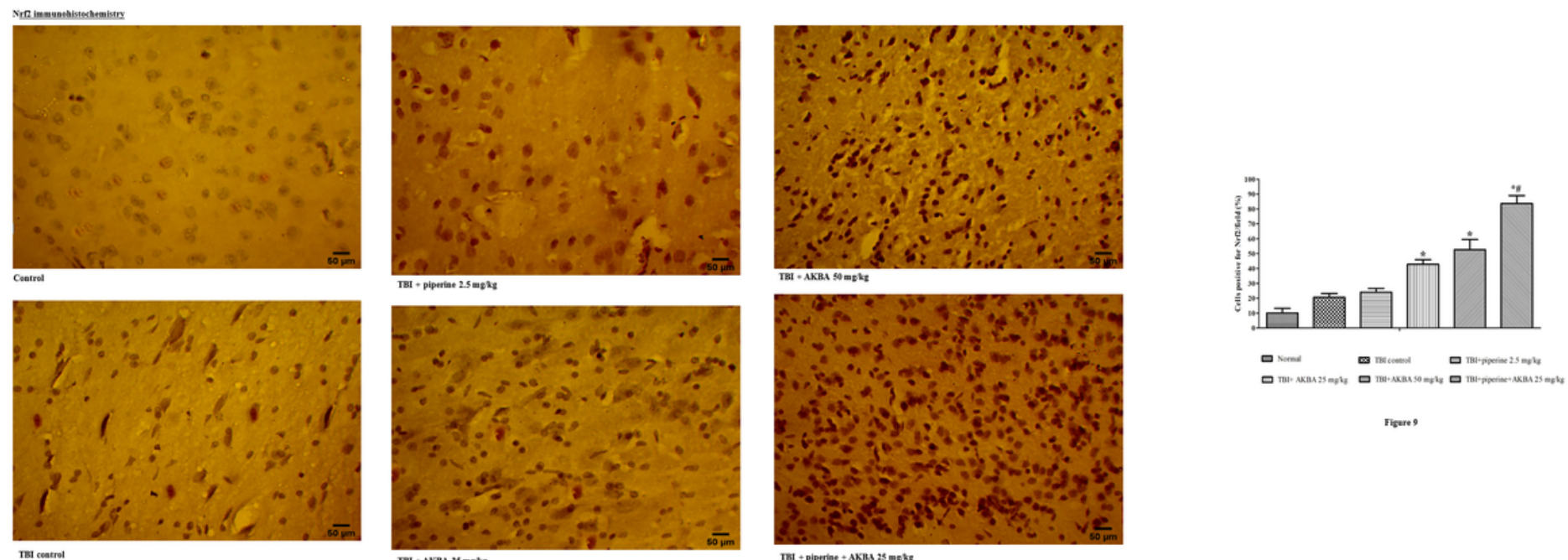

nit + AKBa $25 \mathrm{mgkg}$

Tait + piperiate + AKRA 25 mgkg

Figure 9

Effect of AKBA in combination with piperine on immuno-histochemical study (Nrf2). As compared with the normal group, TBI control group significantly presented a morphology with more Nrf2 nucleus concentration. AKBA $25 \mathrm{mg} / \mathrm{kg}$ and $50 \mathrm{mg} / \mathrm{kg}$ significantly increased the numbers of Nrf2 positive cell ( ${ }^{*} p<0.001$ vs TBI control). After treating with AKBA and piperine combination, the concentration morphology was more apparent (\#p<0.001 vs TBI+ AKBA $50 \mathrm{mg} / \mathrm{kg}$ ). Graph represents the number of positive Nrf2 cells per field.
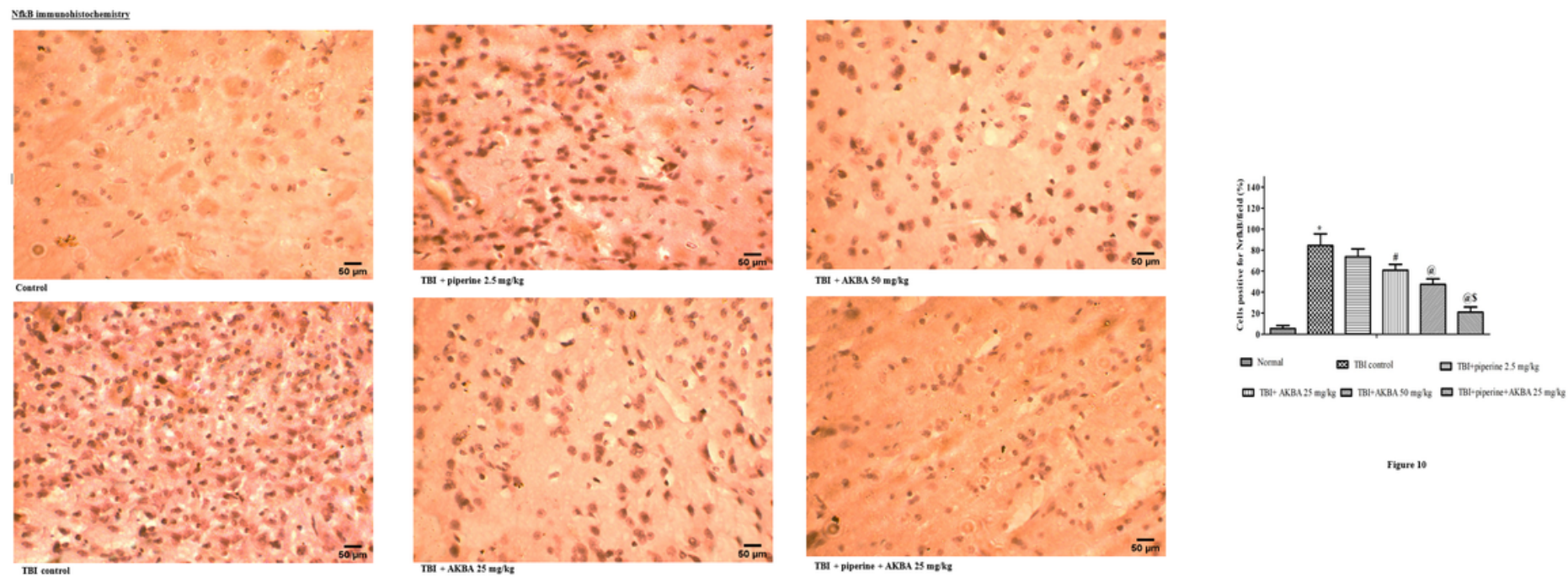
Figure 10

Effect of AKBA in combination with piperine on immuno-histochemical study (NFkB). As compared with the normal group, TBI control group significantly presented a morphology with more NfkB nucleus concentration ( ${ }^{*} \mathrm{P}<0.001$ ). AKBA $25 \mathrm{mg} / \mathrm{kg}$ treated group significantly reduced the level of nuclear $\mathrm{NfkB}$ $(\# P<0.05)$. AKBA $50 \mathrm{mg} / \mathrm{kg}$ treated group significantly decreased the NfkB level $(@ P<0.01)$. After administering AKBA $(25 \mathrm{mg} / \mathrm{kg})$ and piperine $(2.5 \mathrm{mg} / \mathrm{kg})$ combination, the concentration morphology was significantly decreased as compared to TBI control group ( $\left.{ }^{*} \mathrm{P}<0.001\right)$ and AKBA $50 \mathrm{mg} / \mathrm{kg}$ treated group $(\$ \mathrm{P}<0.01)$. Graph represents the number of positive NfkB cells per field. 